\section{The Plate Efficiency of a Continuous Alcohol Still ${ }^{1}$ \\ [ABSTRACT]}

By Clark S. Robinson

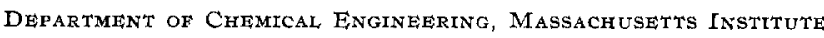
of Technology, Cambridge, Mass.

$\mathrm{T}$ HREE tests on a continuous alcohol still under varying conditions indicated average plate efficiency of from 24 to 56 per cent.

The equations developed by W. K. Lewis for the calculation of the number of plates for a fractionating column ${ }^{2}$ require two things for their use, first, the relation between the vapor and liquid compositions, and, second, the plate efficiency. $\mathrm{Up}$ to the present time nothing regarding the latter has been available in the literature.

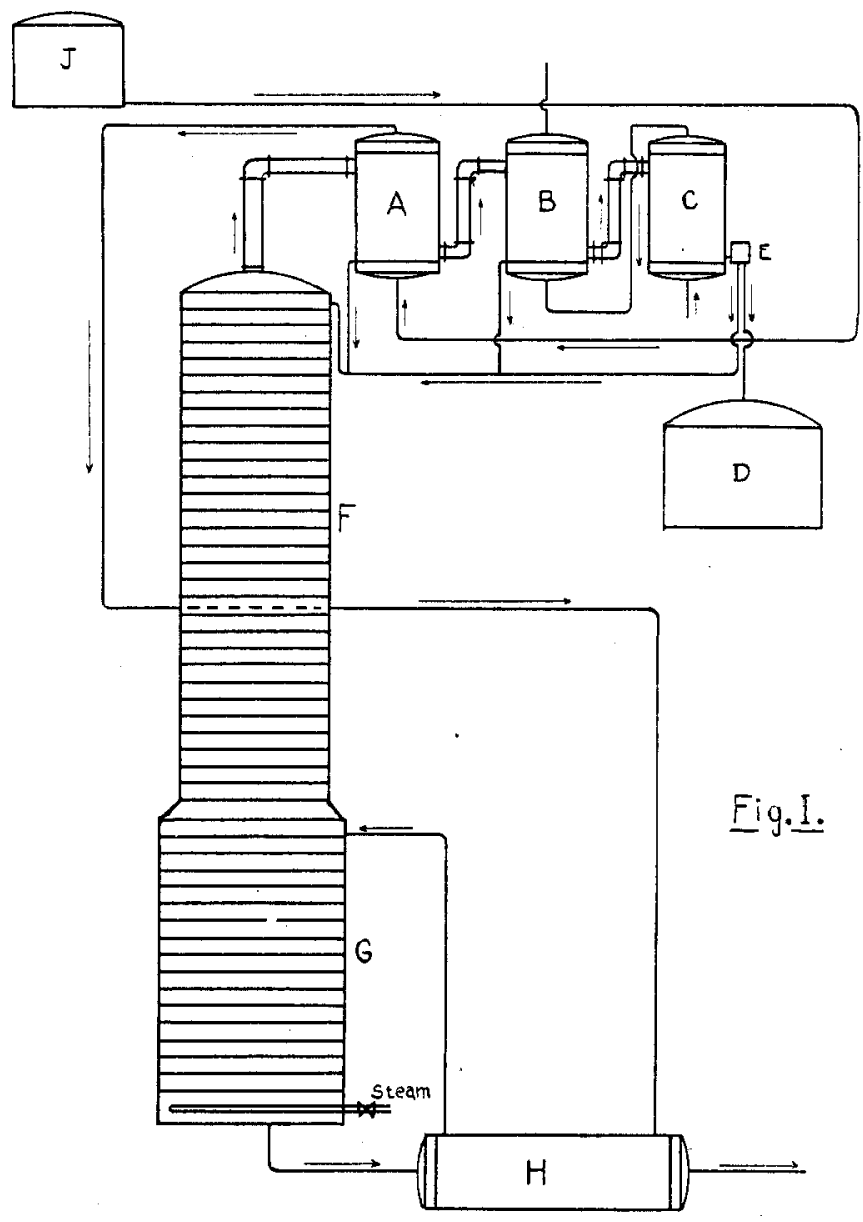

The writer has obtained three careful tests on a continuous still handling ethyl alcohol-water mixtures. This still is of the modern Barbet type with plates fitted with boiling caps as described by Barbet ${ }^{3}$ and by Mariller. ${ }^{4}$ The still is illustrated in Fig. 1.

It consisted of a rectifying column, $\mathrm{F}$, of 30 plates, 1.52 $\mathrm{m}$. in diameter and an exhausting column, $\mathrm{G}$, of 16 plates; $1.65 \mathrm{~m}$. in diameter. The dilute alcohol was taken from a

1 Published as Contribution No. 6 from the Department of Chemical Engineering, M. I, T.

2"The Calculation of the Efficiency and the Design of Rectifying Columns," see page 492 , this issue.

"La Rectification et les Colonnes Rectificatrices en Distillerie," Paris, 1895, 2nd edition.

"La Distillation Fractionée et la Rectification," Paris, 1917. feed tank, J, through condenser A where it was partly heated, then to a heat interchanger, $\mathrm{H}$, where it was heated nearly to the boiling point, and was then delivered on to the top plate of the exhausting column.

The vapor leaving the top of the rectifying column was partly condensed in the condensers $\mathrm{A}$ and $\mathrm{B}$, and the residual vapor was totally condensed in the condenser $\mathrm{C}$. The liquid from condensers $\mathrm{A}$ and $\mathrm{B}$ and a portion of that from $\mathrm{C}$ was returned to the top of the rectifying column as reflux, the remainder of that from $\mathrm{C}$ being withdrawn through suitable coolers to the receiver $\mathrm{D}$. Cooling water flowed through condensers $\mathrm{C}$ and $\mathrm{B}$ in series.

The averaged data on an hourly basis are listed in Table I:

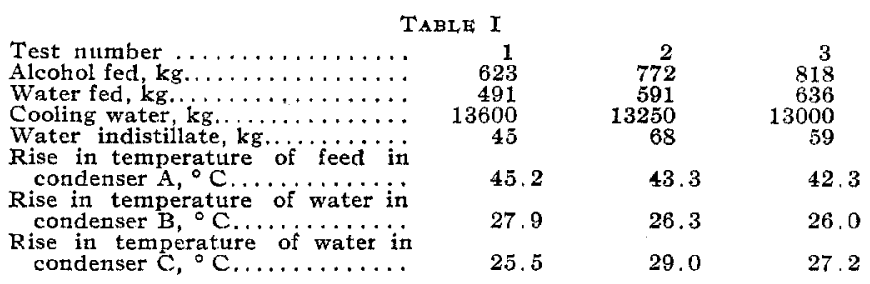

In all cases the amount of alcohol in the waste was too small to be measured.

It was found possible to determine the average plate efficiency of the still for these tests by means of the equations:

$\frac{d x}{d n}=k\left(y_{n}-x_{n}\right)-\frac{k}{\mathrm{R}_{n}}\left(y_{c}-y_{n}\right)$ for the rectifying column and $\frac{d n}{d m}=k\left(y_{m}-x_{m}\right)-\frac{k\left(\mathbf{R}_{f}-1\right)}{\mathbf{R}_{m}}\left(y_{m}-x_{w}\right)$ for the exhausting column, these equations having the significance indicated in the abovementioned paper. ${ }^{2}$

Taeulated Calculations

Test number $\ldots \ldots \ldots \ldots \ldots \ldots \ldots$

Kg. moles alcohoi in product. . . . . . .

$\mathrm{Kg}$. moles water in product

Mole fraction alcohol in product. ......

Heat removed by product $(M L=9,500)$

(Kal.).

(Kal.)................................... Moles reflux from condenser

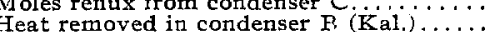

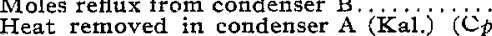

$=0.95$ )

Moles teflux

Total moles reflux.

Reflux ratio (refux: product) $\cdots \cdots \ldots$

Mole fraction alcohol in reflux from con

denser $B$ assuming simple condensation.

Moles alcohol leaving condenser $A$ in

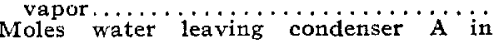

Total moles leaving condenser $\ddot{A}$ in

vapor........................

Moles fraction alcohol in vapor from con

denser A...' ' alcohol in reflux from con-

denser $A$ assuming simple condensation.

Moles alcohol leaving column..........

Moles alcohol leaving column...

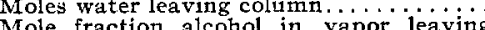

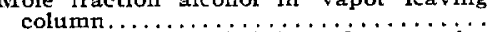

Mole fraction alcohol in reflux entering

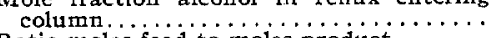

Ratio moles feed to moles product..........

\begin{tabular}{|c|c|c|}
\hline $\begin{array}{c}1 \\
13.5 \\
2.5 \\
0.842 \\
346,000\end{array}$ & $\begin{array}{c}2 \\
16.7 \\
3.97 \\
0.816 \\
384,000\end{array}$ & $\begin{array}{r}3 \\
17.7 \\
3.28 \\
0.844 \\
354,000\end{array}$ \\
\hline $\begin{array}{c}153,000 \\
193,000 \\
20.3 \\
379,000 \\
39.9\end{array}$ & $\begin{array}{c}195,000 \\
189,000 \\
19.8 \\
249,000 \\
36,7\end{array}$ & $\begin{array}{c}200,000 \\
154,000 \\
16.1 \\
339,000 \\
35.5\end{array}$ \\
\hline $\begin{array}{c}48,000 \\
5.05 \\
65.2 \\
4.06\end{array}$ & $\begin{array}{c}56,000 \\
5.9 \\
62.4 \\
3.04\end{array}$ & $\begin{array}{c}58,000 \\
6.1 \\
57.7 \\
2.75\end{array}$ \\
\hline 0.835 & 0.800 & 0.837 \\
\hline 63.9 & 62.3 & 61.1 \\
\hline 12.3 & 14,8 & 11.6 \\
\hline 76.2 & 77.1 & 72.7 \\
\hline 0.839 & 0.808 & 0.840 \\
\hline $\begin{array}{l}0.830 \\
68.1 \\
81.3\end{array}$ & $\begin{array}{l}0.790 \\
67.0 \\
83.0\end{array}$ & $\begin{array}{l}0.833 \\
66.2 \\
78.8\end{array}$ \\
\hline 0.838 & 0.807 & 0.839 \\
\hline $\begin{array}{l}0.835 \\
2.54 \\
0.332\end{array}$ & $\begin{array}{l}0.803 \\
2.41 \\
0.338\end{array}$ & $\begin{array}{l}0.837 \\
2.52 \\
0.335\end{array}$ \\
\hline
\end{tabular}

It was then possible to calculate values of $\frac{d n}{d x}$ and $\frac{d m}{d x}$ for varying values of $x$ from the above formulas. This has been done for Test 1 as follows, the values of $x$ and $y$ being calculated from the vapor composition curve given by $W$. K. Lewis. ${ }^{5}$ Since no measurement of the alcohol in the waste was given, $x_{w}$ was assumed to be 0.0001 , a value probably somewhere near the fact. The calculated values are plotted in Fig. 2.

" "Vapor Composition of Alcohol-Water Mixtures," Thrs Journal, $12(1920), 496$. 